Article

\title{
Femtosecond Laser Processing of Thick Film Cathodes and Its Impact on Lithium-Ion Diffusion Kinetics
}

\author{
Wilhelm Pfleging ${ }^{1,2, *}$ and Petronela Gotcu ${ }^{1}$ (D) \\ 1 Institute for Applied Materials (IAM-AWP) Karlsruhe Institute of Technology, P.O. Box 3640, \\ 76021 Karlsruhe, Germany \\ 2 Karlsruhe Nano Micro Facility (KNMF), H.-von-Helmholtz-Pl. 1, 76344 Egg.-Leopoldshafen, Germany \\ * Correspondence: wilhelm.pfleging@kit.edu; Tel.: +49-721-8906-22889
}

Received: 29 July 2019; Accepted: 27 August 2019; Published: 2 September 2019

\begin{abstract}
Quantitative experiments of lithiation/delithiation rates were considered for a better understanding of electrochemical intercalation/deintercalation processes in laser structured thick film cathodes. Besides galvanostatic cycling for evaluation of specific discharge capacities, a suitable quantitative approach for determining the rate of Li-ion insertion in the active material and the rate of Li-ion transport in the electrolyte is expressed by chemical diffusion coefficient values. For this purpose, the galvanostatic intermittent titration technique has been involved. It could be shown that laser structured electrodes provide an enhanced chemical diffusion coefficient and an improved capacity retention at high charging and discharging rates.
\end{abstract}

Keywords: 3D battery; laser ablation; diffusion coefficient; lithium-ion batteries; $\mathrm{LiCoO}_{2}$

\section{Introduction}

For portable electronic applications, Sony introduced a high-voltage and high-energy density lithium-ion battery (LIB) that consists of amorphous carbon as anode and lithium cobalt oxide, $\mathrm{LiCoO}_{2}$, as cathode material more than 28 years ago. The public demand for high power energy storage systems is on a continuous ascending path. Nowadays, lithium-ion batteries (LIBs) have become an essential tool for the storage of electric energy [1-3]. In state-of-the art LIBs, the thick film electrodes consist at least of active materials, additional binder, and conductive agents, with specific requirements regarding stoichiometry, porosity, and particle size distribution. For high power and high energy applications in full electrical vehicles, numerous lithium-ion pouch cells are used with capacities of each larger than $50 \mathrm{Ah}$ [4]. New electro-mobility concepts appear to be the most appropriate solution for replacing the so far dominating combustion-related mobility and meeting high environment-saving standards. It is assumed that the further development of LIB technology will finally provide an energy storage concept that will meet the requirements of the automotive industry, in terms of energy and power density [5].

To further increase the energy density on cell-level, the so-called mass loading, thus the amount of active material or specific capacity per electrode area has to be increased. This can be achieved by an increase of electrode layer thickness and a reduction of film porosity. However, these approaches are limited regarding their impact on cell performance. With increasing electrode layer thickness and/or decreasing film porosity, an increase of cell resistance and decrease of power density are observed, which is due to an increased diffusion overpotential at high $C$ rates and to the hampered transport of electrons $\left(\mathrm{e}^{-}\right)$and lithium-ions $\left(\mathrm{Li}^{+}\right)$in the composite electrodes. Another approach to increase the energy density is to introduce high energy materials, such as nickel-rich Lithium-Nickel-Manganese-Oxide (NMC) cathodes [6] or silicon and silicon/graphite anodes [7]. The total amount of energy stored in 2D LIBs electrodes is, in general, restricted by their areal footprints due to limitations of achievable film thicknesses for conventional electrode architectures, i.e., 2 dimensional (2D) cell designs. As a result, 
the transport properties of the active material and within the electrode layer need to be improved. This can be realized by nano-scaling or downsizing of the active material powder. Hereby, the interface between particle and electrolyte is increased to reduce the lithium-ion diffusion pathways from active material into the liquid electrolyte and vice versa. Small particle sizes, in turn, lead to increased agglomeration during slurry preparation. Furthermore, a larger quantity of conductive additive is needed to build-up an electrical conductive network. The aggregates that consist of nanoparticles and an increased amount of inactive material (conductive additive) lead to a reduction of the packing density in the electrode, and thus to a decrease of energy density at the cellular level. Furthermore, an enlarged interface between particle and liquid electrolyte leads to an enhancement of the interface reactivity, i.e., a loss of capacity by Solid Electrolyte Interphase (SEI) formation and an enhanced charge transfer resistance will be observed.

Another approach for improving battery performances is the development of three-dimensional (3D) electrode architectures in LIBs for overcoming problems during battery operation, such as power losses, high inter-electrode ohmic resistances [8,9], and mechanical degradation. The latter one is caused by lithium intercalation or de-intercalation and related material expansion or compression $[7,10,11]$. Electrodes with 3D architecture are developed to promote high surface area, high rate capability, high cycle lifetime, and less time-and-cost consuming electrolyte filling [12-15]. In general, a 3D electrode design combines an increased active mass load with a reduced lithium-ion diffusion length, which correlates to an increased energy density and power density, respectively [8]. Several concepts that are based on micro- and nanostructured electrode architectures were proposed for 3D micro-batteries, which could potentially double the energy density by fully utilizing the limited available space [16-18].

Micro-structuring is a modified approach for nano-sized active material particles. Thereby, the particle itself is not changed, but the particle-electrode-structure is adapted. This can be done by the introduction of 3D electrode architectures while using laser ablation of compact or composite cathode and anode materials [15,19-23]. Hereby, a change of the electrode manufacturing process is not necessary. In addition, it is easier to scale-up the process of generation of 3D structures for large footprint areas and layer thicknesses $(\geq 100 \mu \mathrm{m})$, which are significantly beyond state-of-the-art batteries. Laser structuring can improve the battery lifetime, cycle stability, and high rate capability. The structuring of the current collector foils can improve the electrode film adhesion, which is a critical aspect for high energy and thick film electrodes [24-26]. With the direct structuring of thick and thin film electrodes, KIT introduced a new battery concept for achieving large areal energy capacities and power densities [14,27]. In the case of lithium-ion battery manufacturing, laser processes are already applied for electrode cutting. A high cutting edge quality with no film delamination can be achieved. No tool wear occurs in comparison to mechanical punching and, thus, an exchange of the cutting tool is not necessary [23]. The limit cases of laser processing can be described by either a thermally-driven treatment or a cold laser ablation. Both scenario types could find application in battery manufacturing. For example, the pure laser annealing of compact thin film electrodes was developed as versatile tool for adjusting battery-active crystalline phases [28-30]. On the other side, cold ablation by ultrafast laser direct writing could be applied to create advanced 3D electrode architectures. It is worth mentioning that, besides improving lithium-ion diffusion kinetics, a tremendous increase in wettability of composite anode and cathode materials with liquid electrolyte can be realized by 3D structured electrodes. It was shown that 3D patterns in electrodes act as capillary structures, which enhances the wettability, reduces cell storage efforts, and improves the electrochemical cell performances [15]. Hereby, a main issue is the laser process up-scaling with respect to large electrode footprint areas, e.g., for batteries in pouch cell design and the laser processing speed, which should be adapted to the standards in battery manufacturing and coating technologies for lithium-ion cells [23].

In this work, ultrashort laser processing was applied to create 3D surface structures in electrodes that were made of $\mathrm{LiCoO}_{2}$ rich cathodes. Appropriate laser parameters were used to obtain a structure depth within the electrode thickness. An enhanced wetting can be obtained for this dimension [15]. Subsequently, laser-structured cathodes were assembled in Swagelok ${ }^{\circledR}$ cells and the capacity retention 
during galvanostatic cycling (GC) while using different current rates ( $C$ rates) were investigated and compared to cells with unstructured cathodes. To compare the lithium-ion transport properties of the cells with different types of cathodes, chemical diffusion coefficients were determined by galvanostatic intermittent titration technique (GITT) as a function of state-of-charge (SOC).

\section{Materials and Methods}

\subsection{Cathode Material and Electrodes}

The used electrodes are made of composite thick film commercial cathode materials (MTI Corporation, USA) that are based on current collector layer represented by the aluminium foil single side coated by a composite layer, with determined properties, as described previously [31]. Such cathode materials are produced by a tape cast process, followed by calendering (final thickness of composite layer of $95 \mu \mathrm{m}$ ), during which the particle-particle contact and the composite adhesion to the current collector are substantially improved. The composite layer contains binder, conductive carbon, and active material rich in lithium cobalt oxide $\left(\mathrm{LiCoO}_{2}\right)$. The main drawbacks of $\mathrm{LiCoO}_{2}$ cathodes, e.g., the high costs, the limited practical capacity due to structural and chemical instabilities at deep charge $\left(x<0.5\right.$ in $\left.\mathrm{Li}_{x} \mathrm{CoO}_{2}\right)$, and the susceptibility to thermal runaway, are compensated by the addition of $\mathrm{LiMn}_{2} \mathrm{O}_{4}$, with lower costs and sufficiently high charge voltage [32]. The advantages of the new chemistries are a more balanced performance and an increased thermal stability of these cathode materials in comparison to that of the individual component.

\subsection{Laser Structuring}

The surfaces of the cathode layers were modified by laser ablation with an ultrafast fiber laser (Tangerine, Amplitude Systèmes, Paris, France), being performed in ambient air down to the current collector. The applied laser process parameters were $515 \mathrm{~nm}$ wavelength, $330 \mathrm{fs}$ pulse duration, $200 \mathrm{kHz}$ repetition rate, $1.5 \cdot 10^{9} \mathrm{~W}$ peak power, $100 \mathrm{~mm} / \mathrm{s}$ laser scan speed, and two scans, $100 \mu \mathrm{m}$ pitch. More details regarding the used laser machining system can be found elsewhere [33].

\subsection{Electrochemical Analysis}

For the electrochemical measurements, a Swagelok ${ }^{\circledR}$ cell design was used with lithium metal (Sigma-Aldrich, St. Louis, MO, USA) as counter electrode and a glass fiber separator (Whatman ${ }^{\circledR}$ grade GF/A, Sigma Aldrich, St. Louis, MO, USA). All cathode types (unstructured, laser structured) were heated in vacuum at $130^{\circ} \mathrm{C}$ for $24 \mathrm{~h}$ prior to the cell assembly. The cells were assembled in an argon-filled glove box (LABmaster sp, M. Braun Inertgas-Systeme GmbH, Garching/München, Germany). The electrolyte was a commercial mixture of ethylene carbonate: dimethyl carbonate (1:1 volume ratio) containing 1M LiPF6 (BASF, Ludwigshafen, Germany). All of the cell tests were started directly after the cell assembly without any previous storage of the cells. The galvanostatic cycling measurements were performed while using a BT2000 battery cycler (Arbin Instruments, College Station, TX, USA), the galvanostatic intermittent titration technique using a VMP3 multipotentiostat-galvanostat (Bio-Logic Science Instruments, Seyssinet-Pariset, France).

\subsubsection{Galvanostatic Measurements}

Electrochemical characterisation of similar cells was previously carried out in our facility labs and is described elsewhere [34,35]. In this study, each measurement was performed on a minimum of three identically made cells. For simplicity, we further refer to a cell containing unstructured or structured cathode materials as reference-cell and laser-cell, respectively. For the galvanostatic measurements, the current rate was successively increased from C/10 to $2 \mathrm{C}$. A low C-rate was chosen at the beginning of the cycle test for the formation of the cells. 


\subsubsection{Galvanostatic Intermittent Titration Technique}

At first, all of the cells were charged and discharge for three times with a constant current of $C / 10$, then hold at a constant voltage until a current of $\mathrm{C} / 100$ was achieved (CC-CV). Prior to the first current pulse, the cells were discharged. For GITT, a current of C/20 was applied for $60 \mathrm{~min}$., followed by a relaxation time of $6 \mathrm{~h}$. After $6 \mathrm{~h}$, a pseudo-equilibrium was achieved, having a voltage difference of less than $0.04 \mathrm{mV} \cdot \mathrm{s}^{-1}$. The number of titration steps was calculated by the change of the stoichiometry $\Delta x$ needed to de-/intercalate all lithium-ions out of/into the host structure

$$
\Delta x=\frac{I_{0} \cdot \tau}{z_{L i} \cdot n \cdot F} .
$$

$I_{0}$ is the applied constant current, $\tau$ is the time interval of the current pulse, $z_{L i}$ is the valence of $\mathrm{Li}$, $n$ is the number of Mole, and $F$ is the Faraday constant.

The diffusion coefficient of Li-ions $D_{\mathrm{Li}^{+}}$was calculated for each titration step while using the following equation recommended by Weppner and Huggins [36] for solid-mixed conducting electrodes:

$$
D_{L i^{+}}=\frac{4}{\pi} \cdot\left(\frac{V_{m} \cdot I_{0}}{S \cdot F \cdot z_{L i}}\right)^{2} \cdot\left(\frac{\frac{d E_{s}}{d x}}{\frac{d E_{\tau}}{d \tau^{0.5}}}\right)^{2}
$$

which is valid for $\tau \cdot D_{L i^{+}} \ll L^{2} . V_{m}$ is the molar volume, $I_{0}$ is the current pulse, $S$ is the electrochemical active area of the electrode-electrolyte interface, given by the product of BET surface area and the active material mass, $F$ is the Faraday constant, $z_{L i}$ is the charge number of $\mathrm{Li}, E_{s}$ a nd $E_{\tau}$ are the steady-state and the transient voltages, respectively, and $L$ is the composite layer thickness. Figure 1 reports a typical current pulse that corresponds to a current rate of $C / 20$ applied for $\tau$ of $1 \mathrm{~h}$, and the measured voltage in a relaxation period of $6 \mathrm{~h}$.

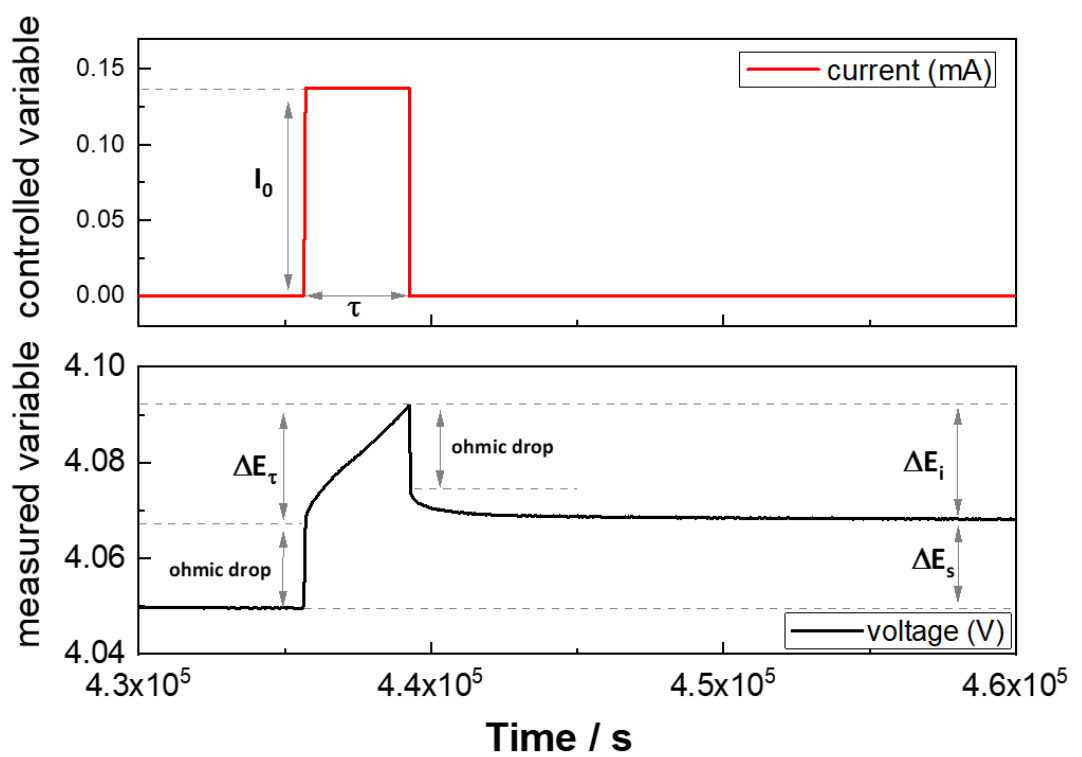

Figure 1. Example of a constant current pulse applied for a known interval of time $\tau$, followed by a relaxation time, while measuring the corresponding potential.

\section{Results and Discussion}

\subsection{Galvanostatic Cycling - Capacity Retention}

Besides SEM, light microscopy (LM) was performed for controlling the ablation depth and surface quality (Figure 2). For this purpose, the top view and the cross section view of both unstructured and 
structured cathodes were analyzed for unstructured and laser structured samples. The ablation depth is almost equal to the layer thickness and the laser ablation process does not damage the current collector.
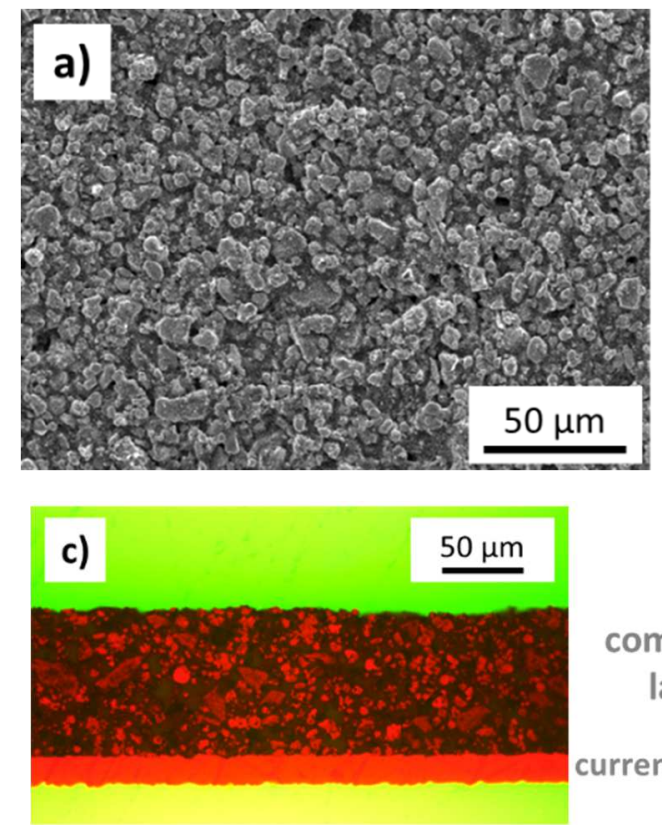
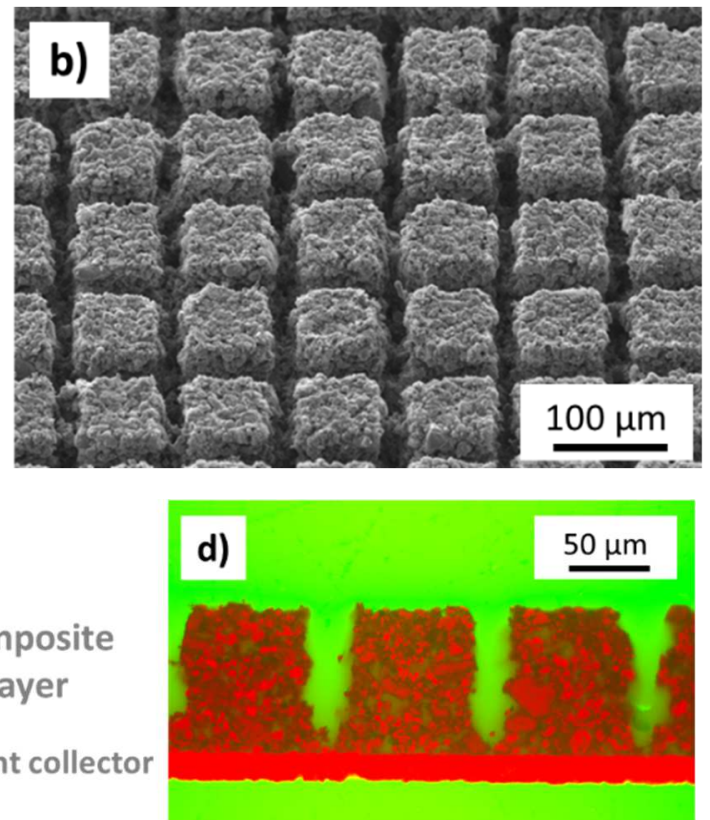

Figure 2. Lithium-ion battery cathode samples- $(\mathbf{a}, \mathbf{b})$ unstructured and $(\mathbf{b}, \mathbf{d})$ structured-based on aluminium foil single-side coated by $\mathrm{LiCoO}_{2}$ rich composite layer. (a,b) SEM images (top view); and, (c,d) light microscopy (LM) images (cross-sectional view). Ablation depth: 90-95 $\mu \mathrm{m}$.

Cells rate capability was determined by applying successively increased C-rates from C/10 up to $2 \mathrm{C}$ (Figure 3). Galvanostatic testing measurements were performed in a voltage range between 3.0 and $4.2 \mathrm{~V} \mathrm{vs} \mathrm{Li} / \mathrm{Li}^{+}$. It was observed that the capacity of the reference-cell is significantly decreased, i.e., at $\mathrm{C} / 2$, its retained capacity is only at $60 \%$, and, furthermore, at $1 \mathrm{C}$ and $2 \mathrm{C}$ such cell shows no capacity anymore. At $2 \mathrm{C}$, the cell with the laser structured electrode still retains about $60 \%$ of its initial discharge capacity. As a final cycling step, the C-rate was set back to $C / 10$ to determine whether any cell degradation occurred during these galvanostatic measurements. A small capacity loss was observed at the end of the measurements: the cell capacity decreased by $6 \%$ and $8 \%$ for the laser-and reference-cells, respectively.

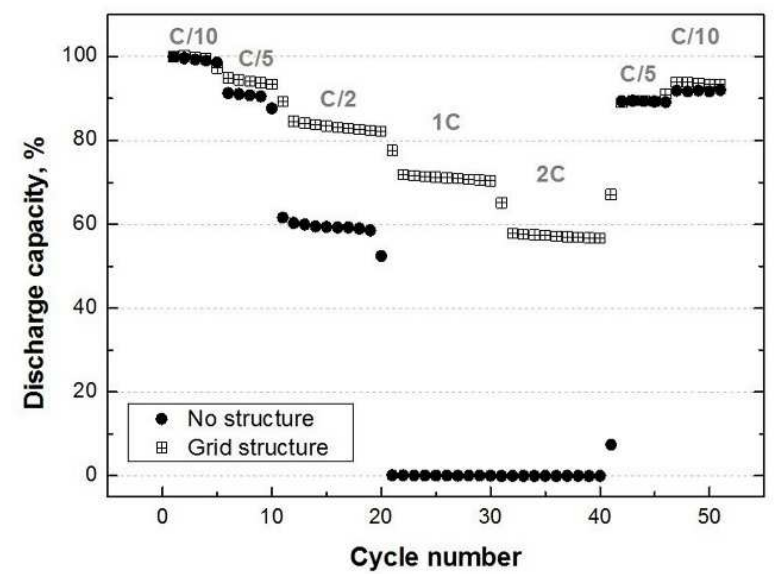

Figure 3. Discharged capacity determined by galvanostatic cycling with potential limitation using different C-rates, performed on reference- and laser-cells. 


\subsection{GITT—Chemical Diffusion Coefficient}

Figure 4 presents the typical behaviour of the transient and steady-state voltages for a reference-cell. As a function of square root of time, the transient voltage change shows usually a linear trend. While using these parameters, the diffusion coefficient for each change in stoichiometry is reported in Figure 5. The product of BET surface area and the active material mass can define the electrochemical active area. For the unstructured and structured electrodes values of $136 \mathrm{~cm}^{2}$ and $93 \mathrm{~cm}^{2}$ are achieved, respectively. The approach is valid for a description of the 2D surface area (dashed line in Figure 5). Further information regarding the composite electrodes, such as mass, density, and porosity, can be extracted from [31].

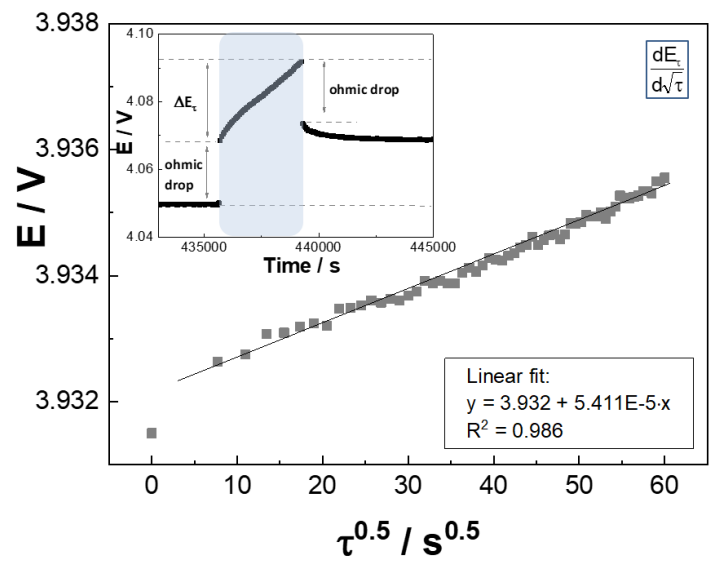

(a)

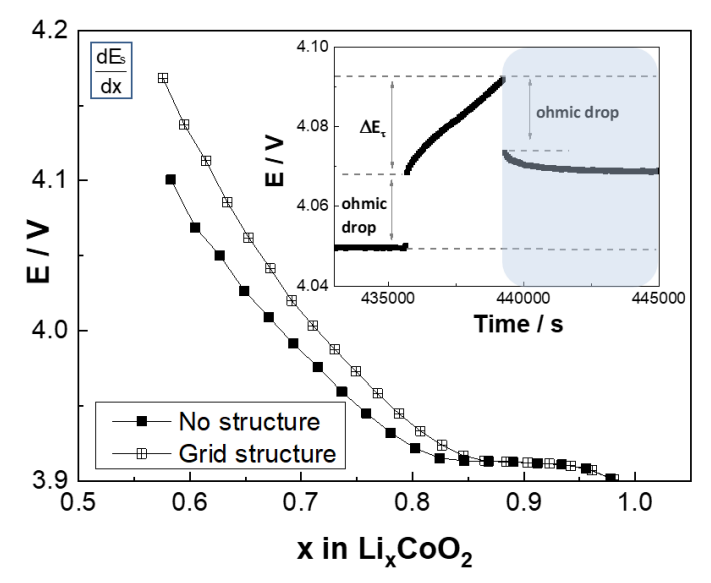

(b)

Figure 4. Measured variables in the galvanostatic intermittent titration technique (GITT) for the evaluation of diffusion coefficient: (a) transient $E_{\tau}$ and (b) equilibrium $E_{s}$ potentials. Insets are illustrating the shaded part of the measured current pulse, which is taken into account for the respective potential.

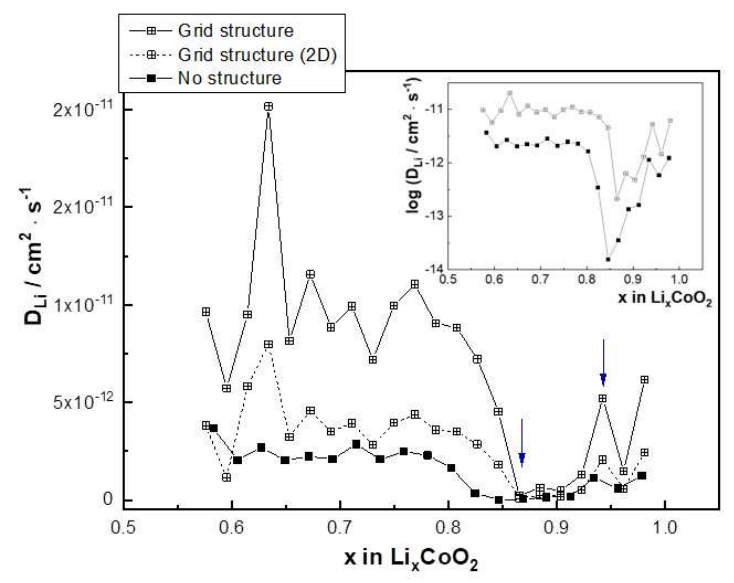

Figure 5. Diffusion coefficient of Li-ions obtained by GITT as a function of stoichiometry. Inset is illustrating the measured diffusion coefficient (log scale) as a function of stoichiometry.

Very recent research results were achieved, in which it could be proven that during discharging the lithium concentration at cathode side is significantly increased on top and along the contour of free-standing microstructures, i.e., the side-walls of laser generated grid structures are getting activated to provide additional Li pathways [37]. Therefore, the impact of the free-standing structures on the electrode surface needs to be included in a three-dimensional (3D) description, for which their contribution relates to the top and surrounding walls of each single structure. Based on the laser parameters used for the 3D structure generation, a decrease of $36 \%$ in surface area (2D) is expected 
along with an increase of over $300 \%$, due to the lateral wall contribution (3D) for the structured cathode layer.

The titration technique offers information in relation to the phase diagram, i.e., the existing phases in the system. The diffusion coefficient corresponding to the laser structured material tends to be more sensitive to the phase transitions. At $x \sim 0.94$ a clear change in the slope is observed, which, according to $[38,39]$, is related to the first order insulator-metal transition. For the $x$ range between 0.94-0.86, the diffusion coefficient is described by a plateau in quite good agreement with the two-phase region that was described in the previous electrochemical studies. The measurements by Reynier et al. [40] found this two-phase region in the $x$ range from 0.95 to 0.83 , whereas lower concentration for $x=0.75$ or 0.80 was reported by $[38,41]$, respectively. Smaller titration steps are needed for a more precise determination of the phase boundaries composition. Nevertheless, in this region, the diffusion coefficients of the two different material types are the lowest achieved (insert graph in Figure 5). Below $x \sim 0.86$ the diffusion coefficient determined for laser structured sample is five times higher than for the unstructured. This range in stoichiometry corresponds to the layered hexagonal single phase [40,42], where the 3D structures seem to have an impact on the kinetic properties. Approaching a lower $x$, i.e., the order-disorder transition known for $x \sim 0.5$, the diffusion coefficient of the cell with structured electrode tends to be more sensitive and it shows a change in slope.

The values of the diffusion coefficients are in the range that is given by previous studies [43], which are influenced by the measurements parameters, voltage range, electrolyte properties, etc. However, the goal of this work was to determine the relative values with respect to the specific design characteristics of reference cell and cell with structured electrode.

A closer look to the titration steps (Figure 6) enables us to distinguish dissimilarities in the voltage changes of each cell. At $x=0.96$ and at a close value of the determined diffusion coefficient for each cathode material, the voltage drop in the reference-cell is significantly higher than in the cell with laser structured electrode. This is also noticed in the hexagonal phase at $x=0.63$, however with a slight smaller effect. The equilibrium potential behaviour at this point clearly indicates a different diffusion-rate, which yields a four times higher diffusion coefficient.

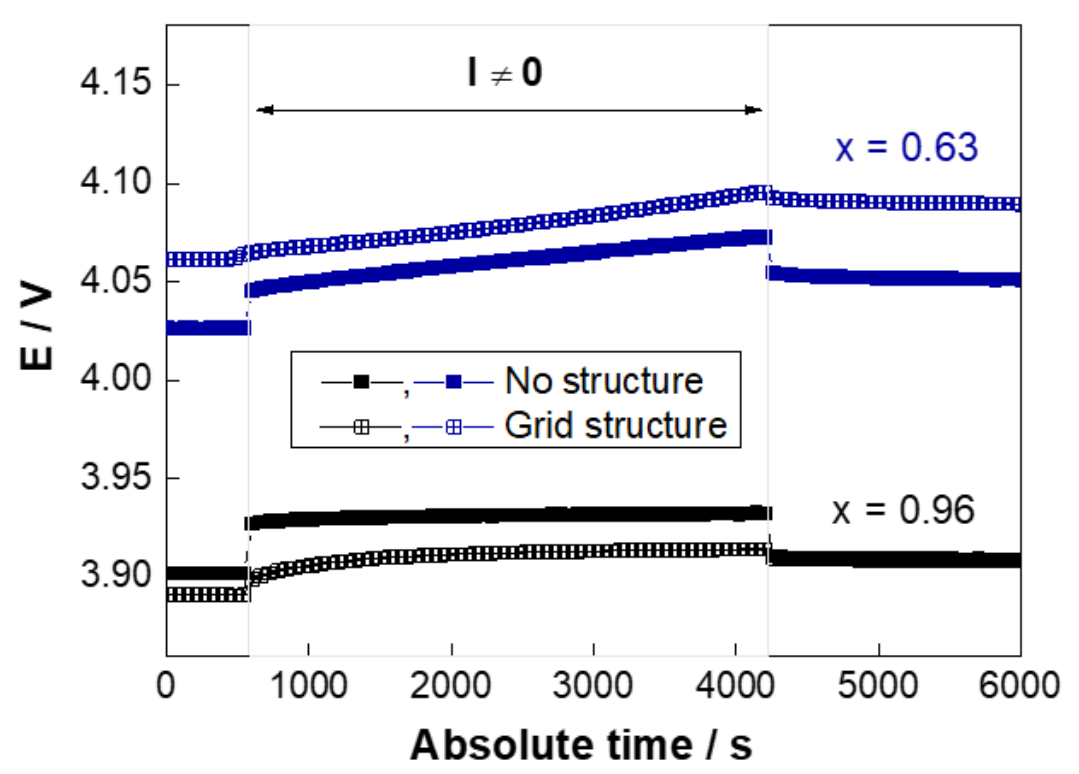

Figure 6. Measured current pulses during GITT from cells with structured (open symbols) and unstructured (solid symbols) electrodes at different state of charge, i.e., different lithium content $x$ in cathode material (black: $x=0.96$, blue $x=0.63$ ).

The voltage loss $\Delta E_{i}$ as function of SOC was determined in order compare the influence of each specific cell design characteristics. Immediately after the current was interrupted a respective steep 
drop in voltage was measured (insert graph in Figure $4 b$ ). This instantaneous drop is mainly due to the ohmic resistance of the cell (ohmic drop), to which a contribution of charge transfer and polarization effect is added. Since the ohmic drop is a very fast process, it could not be separated here. The instantaneous cell impedance, calculated as the ratio of the instantaneous voltage drop and current, of reference-cell is factor 3 higher than of the cell with laser structured electrode (Figure 7). As the cell impedance is dependent on current, this is expected to increase with increasing current densities.

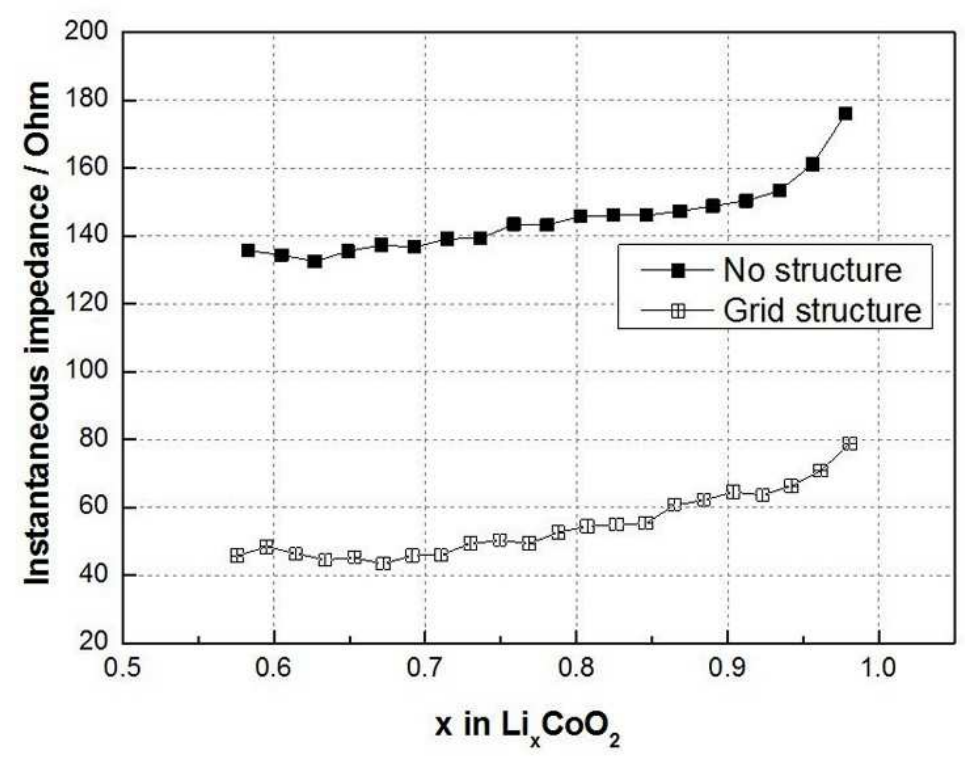

Figure 7. Instantaneous impedance as a function of lithium stoichiometry in the cathode.

\section{Conclusions}

For lithium-ion battery manufacturing, ultrafast laser structuring of composite electrodes offers great advantages regarding the improvement of cell performance such as an increased battery lifetime and improved cycle retention for high charging and discharging rates. It was shown that an appropriate 3D surface topography has a positive impact on the capacity retention, especially for high $\mathrm{C}$ rates. An increased active surface area influences the diffusion kinetics of lithium-ions in the electrode materials through the electrolyte, whereas critical mechanical tensions during charging/discharging can be avoided by using electrode architectures with free-standing pillars. The chemical lithium diffusion coefficient as function of state-of-charge was measured for cells with structured and unstructured cathodes. It could be shown that the diffusion coefficient, especially for cells with laser structured electrodes, is quite sensitive to the respective phase in the system. Furthermore, the ohmic losses are significantly reduced inside the electrochemical cell by using the laser structured electrodes. For future battery manufacturing, a balanced combination of 3D battery and thick film concept will enable the development of a new generation of high power and high energy lithium-ion cells.

Author Contributions: Conceptualization, P.G. and W.P.; methodology, P.G. and W.P.; validation, P.G. and W.P.; investigation, P.G. and W.P.; resources, P.G. and W.P.; data curation, P.G. and W.P.; writing-original draft preparation, P.G. and W.P.; writing-review and editing, P.G. and W.P.; supervision, P.G. and W.P.

Funding: This research was funded by German Research Foundation (DFG), project No. 392322200.

Acknowledgments: This project has received funding from the German Research Foundation (DFG, project No. 392322200). Finally, the support for laser materials processing from the Karlsruhe Nano Micro Facility (KNMF, http://www.knmf.kit.edu/), a Helmholtz research infrastructure at the Karlsruhe Institute of Technology (KIT), is gratefully acknowledged.

Conflicts of Interest: The authors declare no conflict of interest. 


\section{References}

1. Goodenough, J.B.; Kim, Y. Challenges for rechargeable Li batteries. Chem. Mater. 2010, 22, 587-603. [CrossRef]

2. Scrosati, B.; Garche, J. Lithium batteries: Status, prospects and future. J. Power Sources 2010, 195, $2419-2430$. [CrossRef]

3. Amatucci, G.; Du Pasquier, A.; Blyr, A.; Zheng, T.; Tarascon, J.M. The elevated temperature performance of the $\mathrm{LiMn}_{2} \mathrm{O}_{4} / \mathrm{C}$ system: Failure and solutions. Electrochim. Acta 1999, 45, 255-271. [CrossRef]

4. Sakti, A. Quantification of Performance and Cost Trajectory of Li-ion Battery Designs for Personal Vehicle Electrification in the Near Future. Ph.D. Thesis, Carnegie Mellon University, Pittsburgh, PA, USA, 2013.

5. Andre, D.; Kim, S.-J.; Lamp, P.; Lux, S.F.; Maglia, F.; Paschos, O.; Stiaszny, B. Future generations of cathode materials: An automotive industry perspective. J. Mater. Chem. A 2015, 3, 6709-6732. [CrossRef]

6. Rakebrandt, J.-H.; Smyrek, P.; Zheng, Y.; Seifert, H.J.; Pfleging, W. Laser processing of thick $\mathrm{Li}(\mathrm{NiMnCo}) \mathrm{O}_{2}$ electrodes for lithium-ion batteries. In Laser-Based Micro-and Nanoprocessing XI; International Society for Optics and Photonics: Bellingham, WA, USA, 2017; Volume 10092, p. 100920M.

7. Zheng, Y.; Seifert, H.J.; Shi, H.; Zhang, Y.; Kübel, C.; Pfleging, W. 3D silicon/graphite composite electrodes for high-energy lithium-ion batteries. Electrochim. Acta 2019, 317, 502-508. [CrossRef]

8. Long, J.W.; Dunn, B.; Rolison, D.R.; White, H.S. Three-dimensional battery architectures. Chem. Rev. 2004, 104, 4463-4492. [CrossRef] [PubMed]

9. Oudenhoven, J.F.M.; Baggetto, L.; Notten, P.H.L. All-Solid-State Lithium-Ion Microbatteries: A Review of Various Three-Dimensional Concepts. Adv. Energy Mater. 2011, 1, 10-33. [CrossRef]

10. Kohler, R.; Besser, H.; Hagen, M.; Ye, J.; Ziebert, C.; Ulrich, S.; Pröll, J.; Pfleging, W. Laser micro-structuring of magnetron-sputtered $\mathrm{SnO}_{\mathrm{x}}$ thin films as anode material for lithium ion batteries. Microsyst. Technol. 2011, 17, 225-232. [CrossRef]

11. Shi, H.; Liu, X.; Wu, R.; Zheng, Y.; Li, Y.; Cheng, X.; Pfleging, W.; Zhang, Y. In Situ SEM Observation of Structured Si/C Anodes Reactions in an Ionic-Liquid-Based Lithium-Ion Battery. Appl. Sci. 2019, 9, 956. [CrossRef]

12. Xia, H.; Wan, Y.H.; Assenmacher, W.; Mader, W.; Yuan, G.L.; Lu, L. Facile synthesis of chain-like $\mathrm{LiCoO}_{2}$ nanowire arrays as three-dimensional cathode for microbatteries. NPG Asia Mater. 2014, 6, e126. [CrossRef]

13. Xiong, W.; Xia, Q.Y.; Xia, H. Three-dimensional self-supported metal oxides as cathodes for microbatteries. Funct. Mater. Lett. 2014, 7, 1430003. [CrossRef]

14. Ferrari, S.; Loveridge, M.; Beattie, S.D.; Jahn, M.; Dashwood, R.J.; Bhagat, R. Latest advances in the manufacturing of 3D rechargeable lithium microbatteries. J. Power Sources 2015, 286, 25-46. [CrossRef]

15. Pfleging, W.; Pröll, J. A new approach for rapid electrolyte wetting in tape cast electrodes for lithium-ion batteries. J. Mater. Chem. A 2014, 2, 14918-14926. [CrossRef]

16. Lim, D.G.; Chung, D.W.; Kohler, R.; Pröll, J.; Scherr, C.; Pfleging, W.; Garcia, R.E. Designing 3D Conical-Shaped Lithium-Ion Microelectrodes. J. Electrochem. Soc. 2014, 161, A302-A307. [CrossRef]

17. Pikul, J.H.; Zhang, H.G.; Cho, J.; Braun, P.V.; King, W.P. High-power lithium ion microbatteries from interdigitated three-dimensional bicontinuous nanoporous electrodes. Nat. Commun. 2013, 4, 1732. [CrossRef] [PubMed]

18. Zhang, H.G.; Yu, X.D.; Braun, P.V. Three-dimensional bicontinuous ultrafast-charge and -discharge bulk battery electrodes. Nat. Nanotechnol. 2011, 6, 277-281. [CrossRef] [PubMed]

19. Pröll, J.; Kim, H.; Piqué, A.; Seifert, H.J.; Pfleging, W. Laser-printing and femtosecond-laser structuring of $\mathrm{LiMn}_{2} \mathrm{O}_{4}$ composite cathodes for Li-ion microbatteries. J. Power Sources 2014, 255, 116-124. [CrossRef]

20. Kohler, R.; Pröll, J.; Bruns, M.; Ulrich, S.; Seifert, H.J.; Pfleging, W. Conical surface structures on model thin-film electrodes and tape-cast electrode materials for lithium-ion batteries. Appl. Phys. A 2013, 112, 77-85. [CrossRef]

21. Kim, H.; Pröll, J.; Kohler, R.; Pfleging, W.; Pique, A. Laser-Printed and Processed $\mathrm{LiCoO}_{2}$ CathodeThick Films for Li-Ion Microbatteries. J. Laser Micro Nanoeng. 2012, 7, 320-325. [CrossRef]

22. Kim, J.S.; Pfleging, W.; Kohler, R.; Seifert, H.J.; Kim, T.Y.; Byun, D.; Jung, H.G.; Choi, W.C.; Lee, J.K. Three-dimensional silicon/carbon core-shell electrode as an anode material for lithium-ion batteries. J. Power Sources 2015, 279, 13-20. [CrossRef]

23. Pfleging, W. A review of laser electrode processing for development and manufacturing of lithium-ion batteries. Nanophotonics 2018, 7, 549-573. [CrossRef] 
24. Tang, X.-X.; Liu, W.; Ye, B.-Y.; Tang, Y. Preparation of current collector with blind holes and enhanced cycle performance of silicon-based anode. Trans. Nonferrous Met. Soc. China 2013, 23, 1723-1727. [CrossRef]

25. Zhang, N.; Zheng, Y.; Trifonova, A.; Pfleging, W. Laser structured Cu foil for high-performance lithium-ion battery anodes. J. Appl. Electrochem. 2017, 47, 829-837. [CrossRef]

26. Zheng, Y.; An, Z.; Smyrek, P.; Seifert, H.J.; Kunze, T.; Lang, V.; Lasagni, A.F.; Pfleging, W. Direct laser interference patterning and ultrafast laser-induced micro/nano structuring of current collectors for lithium-ion batteries. In Laser-based Micro-and Nanoprocessing X; International Society for Optics and Photonics: Bellingham, WA, USA, 2016; Volume 9736, p. 97361B.

27. Notten, P.H.L.; Roozeboom, F.; Niessen, R.A.H.; Baggetto, L. 3-D integrated all-solid-state rechargeable batteries. Adv. Mater. 2007, 19, 4564-4567. [CrossRef]

28. Kohler, R.; Smyrek, P.; Ulrich, S.; Bruns, M.; Trouillet, V.; Pfleging, W. Patterning and annealing of nanocrystalline $\mathrm{LiCoO}_{2}$ thin films. J. Optoelectron. Adv. Mater. 2010, 12, 547-552.

29. Pröll, J.; Kohler, R.; Torge, M.; Ulrich, S.; Ziebert, C.; Bruns, M.; Seifert, H.J.; Pfleging, W. Laser microstructuring and annealing processes for lithium manganese oxide cathodes. Appl. Surf. Sci. 2011, 257, 9968-9976. [CrossRef]

30. Pröll, J.; Weidler, P.G.; Kohler, R.; Mangang, A.; Heissler, S.; Seifert, H.J.; Pfleging, W. Comparative studies of laser annealing technique and furnace annealing by X-ray diffraction and Raman analysis of lithium manganese oxide thin films for lithium-ion batteries. Thin Solid Films 2013, 531, 160-171. [CrossRef]

31. Gotcu, P.; Seifert, H.J. Thermophysical properties of $\mathrm{LiCoO}_{2}-\mathrm{LiMn}_{2} \mathrm{O}_{4}$ blended electrode materials for Li-ion batteries. Phys. Chem. Chem. Phys. 2016, 18, 10550-10562. [CrossRef]

32. Manthiram, A.; Muraliganth, T. Lithium Intercalation Cathode Materials for Lithium-Ion Batteries. In Handbook of Battery Material; Daniel, C., Besenhar, J.O., Eds.; Wiley-VCH: Weinheim, Germany, 2011; pp. 343-375.

33. Mangang, M.; Seifert, H.J.; Pfleging, W. Influence of laser pulse duration on the electrochemical performance of laser structured $\mathrm{LiFePO}_{4}$ composite electrodes. J. Power Sources 2016, 304, 24-32. [CrossRef]

34. Smyrek, P.; Pröll, J.; Seifert, H.J.; Pfleging, W. Laser-Induced Breakdown Spectroscopy of Laser-Structured $\mathrm{Li}(\mathrm{NiMnCo}) \mathrm{O}_{2}$ Electrodes for Lithium-Ion Batteries. J. Electrochem. Soc. 2016, 163, A19-A26. [CrossRef]

35. Gotcu, P.; Pfleging, W.; Smyrek, P.; Seifert, H.J. Thermal behaviour of $\mathrm{LixMeO}_{2}(\mathrm{Me}=\mathrm{Co}$ or $\mathrm{Ni}+\mathrm{Mn}+\mathrm{Co})$ cathode materials. Phys. Chem. Chem. Phys. 2017, 19, 11920-11930. [CrossRef] [PubMed]

36. Weppner, W.; Huggins, R.A. Determination of the Kinetic Parameters of Mixed-Conducting Electrodes and Application to the System $\mathrm{Li}_{3} \mathrm{Sb}$. J. Electrochem. Soc. 1977, 124, 1569-1578. [CrossRef]

37. Smyrek, P.; Bergfeldt, T.; Seifert, H.J.; Pfleging, W. Laser-induced breakdown spectroscopy for the quantitative measurement of lithium concentration profiles in structured and unstructured electrodes. J. Mater. Chem. A 2019, 7, 5656-5665. [CrossRef]

38. Reimers, J.N.; Dahn, J.R. Electrochemical and Insitu X-Ray-Diffraction Studies of Lithium Intercalation in $\mathrm{Li}_{\mathrm{x}} \mathrm{CoO}_{2}$. J. Electrochem. Soc. 1992, 139, 2091-2097. [CrossRef]

39. Chen, Z.H.; Dahn, J.R. Methods to obtain excellent capacity retention in $\mathrm{LiCoO}_{2}$ cycled to 4.5 V. Electrochim. Acta 2004, 49, 1079-1090. [CrossRef]

40. Reynier, Y.; Graetz, J.; Swan-Wood, T.; Rez, P.; Yazami, R.; Fultz, B. Entropy of Li intercalation in $\mathrm{LixCoO}_{2}$. Phys. Rev. B 2004, 70, 174304. [CrossRef]

41. Reimers, J.N.; Dahn, J.R.; Vonsacken, U. Effects of Impurities on the Electrochemical Properties of $\mathrm{LiCoO}_{2}$. J. Electrochem. Soc. 1993, 140, 2752-2754. [CrossRef]

42. Chang, K.; Hallstedt, B.; Music, D.; Fischer, J.; Ziebert, C.; Ulrich, S.; Seifert, H.J. Thermodynamic description of the layered $\mathrm{O}_{3}$ and $\mathrm{O}_{2}$ structural $\mathrm{LiCoO}_{2}-\mathrm{CoO}_{2}$ pseudo-binary systems. Calphad 2013, 41, 6-15. [CrossRef]

43. Hong, J.S.; Selman, J.R. Relationship between calorimetric and structural characteristics of lithium-ion cells-II. Determination of Li transport properties. J. Electrochem. Soc. 2000, 147, 3190-3194. [CrossRef]

(C) 2019 by the authors. Licensee MDPI, Basel, Switzerland. This article is an open access article distributed under the terms and conditions of the Creative Commons Attribution (CC BY) license (http://creativecommons.org/licenses/by/4.0/). 